\title{
Padrões espaciais e ecológicos de espécies arbóreas refletem a estrutura em mosaicos de uma floresta subtropical
}

\author{
Alexandre Copatti Loregian ${ }^{1}$, Bruno Barbosa Silva ${ }^{1}$, Elisabete Maria Zanin ${ }^{2}$, \\ Vanderlei Secretti Decian ${ }^{2}$, Carlos Henke-Oliveira ${ }^{3}$ e Jean Carlos Budke ${ }^{1,4}$
}

Recebido em 3/08/2011. Aceito em 14/05/2012

\begin{abstract}
RESUMO
(Padrões espaciais e ecológicos de espécies arbóreas refletem a estrutura em mosaicos de uma floresta subtropical). A abundância e distribuição espacial das espécies podem ser reflexos das necessidades do seu nicho ecológico, além de reflexos das variações ambientais no tempo e espaço. Os objetivos do presente trabalho foram analisar a distribuição espacial e grupos ecológicos das espécies arbóreas em um remanescente de floresta subtropical e avaliar a interferência destes padrões sobre métricas de riqueza e diversidade. Os padrões espaciais foram avaliados considerando uma área amostral de 1 ha dividida em unidades amostrais contíguas de $10 \times 10 \mathrm{~m}$, onde todos os indivíduos com perímetro à altura do peito $\geq 15 \mathrm{~cm}$ foram amostrados. A descrição dos padrões foi obtida por meio de correlogramas (índice I de Moran), considerando diversas classes de distância, índices de agregação e diagramas de superfície. A co-ocorrência entre espécies foi analisada por meio de índices de associação espacial. A maioria das espécies apresentou distribuição agrupada e com autocorrelação espacial positiva, sobretudo para as menores classes de distância, indicando a formação de pequenos grupos de indivíduos. Da mesma forma, 17 espécies apresentaram associações espaciais (co-ocorrências), formando densos agrupamentos e, embora não tenham interferido sobre a riqueza específica, Casearia sylvestris e Ocotea diospyrifolia diminuíram a equabilidade em alguns setores da área. Espécies tolerantes à sombra apresentaram-se associadas, bem como, espécies dependentes de luz, indicando que a dinâmica de mosaicos pode interferir diretamente sobre a distribuição das espécies, sobretudo pela limitação de dispersão.
\end{abstract}

Palavras-chave: autocorrelação espacial, correlogramas, índices de distância, limitação de dispersão, riqueza de espécies

\begin{abstract}
(Spatial and ecological patterns of tree species reflect patch dynamics of a subtropical forest). The abundance and spatial distribution of species may reflect on niche requirements, interactions among individuals and across as time and space. In this way, the aims of this work were to analyze tree species distribution and ecological groups in a remnant of subtropical forest to evaluate the interference of such patterns over richness and diversity metrics. We evaluated the spatial patterns of a 1 ha area divided into $10 \times 10 \mathrm{~m}$ sampling units where we surveyed all living trees with perimeter at breast height $\geq 15 \mathrm{~cm}$. Pattern descriptions were obtained by using correlograms (Moran's I) over several distance classes, aggregation indices and surface diagrams. The co-occurrence among species was obtained by using spatial association indices. Furthermore, 17 species showed aggregated distribution and positive spatial autocorrelation, mainly in the shorter distance classes, which indicated the occurrence of several small groups of individuals. In addition, many species were spatially associated with dense groups and although such groups do not influence species richness, Casearia sylvestris and Ocotea diospyrifolia led to lower equability in some stands. Shade tolerant species were associated well as light demanding ones, which indicates that patch dynamics may interfere directly on species distribution, mainly by dispersal limitation.
\end{abstract}

Key words: correlograms, dispersion limitation, distance indices, spatial autocorrelation, species richness

\footnotetext{
${ }^{1}$ Universidade Regional Integrada do Alto Uruguai e das Missões, Depto. de Ciências Biológicas, Laboratório de Sistemática e Ecologia Vegetal, Erechim, RS, Brasil

${ }^{2}$ Universidade Regional Integrada do Alto Uruguai e das Missões, Depto. de Ciências Biológicas, Laboratório de Geoprocessamento e Planejamento Ambiental, Erechim, RS, Brasil

${ }^{3}$ Universidade de Brasília, Departamento de Ecologia, Brasília, DF, Brasil

${ }^{4}$ Autor para correspondência: jean@uricer.edu.br
} 


\section{Introdução}

O entendimento dos padrões de distribuição de espécies é um importante foco em estudos em comunidades vegetais, uma vez que permite testar hipóteses sobre processos que ocorreram no passado, além de ser imprescindível para o entendimento de processos que poderão ocorrer tanto para as próprias plantas quanto para os organismos com os quais elas interagem (Dale 1997). Neste sentido, a abundância e a distribuição espacial das espécies nas comunidades vegetais podem ser reflexos das necessidades do seu nicho ecológico, além de reflexos das variações ambientais no tempo e espaço (Poulos \& Camp 2010). Por outro lado, contrário às expectativas oriundas da teoria baseada em nicho, a teoria neutra prediz que a limitação de dispersão, especiação e o papel da estocasticidade ao longo do tempo podem levar espécies ecologicamente equivalentes a formarem padrões de distribuição e abundância similares àqueles observados na natureza (Hubbell 2001).

Conforme enfatizado por Gilbert \& Lechowics (2004), tanto a hipótese baseada em nicho quanto à hipótese da teoria neutra são de difícil distinção em comunidades naturais, pois as mudanças ambientais são geralmente autocorrelacionadas espacialmente, incorporando um componente geográfico-espacial inerente. Desta forma, a distinção entre fatores puramente ambientais, puramente espaciais e aqueles ambientais estruturados no espaço tem demonstrado que quando isolados, a explicação aferida pela variação espacialmente estruturada é maior do que a variação associada puramente ao ambiente. Em adição, processos associados à teoria de nicho são mais nítidos quanto maior a escala considerada, incorporando desta forma, diversos ambientes (Tuomisto et al. 2003). Assim, espera-se que em escalas mais amplas, as adaptações para regimes ambientais específicos possuam uma interface para uma perspectiva baseada em nicho, enquanto que em escalas locais ou intermediárias, a covariância entre ambiente e distância geográfica torne mais difícil a distinção entre processos neutros e aqueles baseados em nicho na estruturação de comunidades (Gilbert \& Lechowics 2004).

Diversos métodos estão sendo empregados para análise de padrões espaciais. Dale et al. (2002) e Perry et al. (2002) forneceram um amplo quadro para a tomada de decisões quanto a análises e interpretações desses padrões espaciais. Diferentemente das análises diretas de interação entre espécie-ambiente (e.g. análise de correspondência canônica - CCA), a análise exploratória gerada pelos métodos de distribuição espacial permitem quantificar a estrutura espacial existente para uma ou mais espécies (tamanho e forma de agrupamentos), possibilitando a identificação de relações entre diferentes estádios ontogenéticos, bem como, a visualização de agregação ou segregação entre distribuições de espécies (Perry et al. 2002).

A região do Alto Uruguai, inserida em áreas de média elevação do planalto sul-brasileiro é caracterizada por ex- tensas áreas com Floresta Ombrófila Mista nas áreas mais elevadas, as quais são gradativamente substituídas por florestas estacionais nas regiões de menor altitude e mais próximas do vale do rio Uruguai (Leyser et al. 2009). Nas áreas de altitude intermediária é possível encontrar espécies de ambas as formações florestais, além de espécies de ampla distribuição e, embora se perceba a transição florística que ocorre ao longo da região, o caráter fisionômico peculiar da Araucaria angustifolia (Bertol.) O.Kuntze, em especial nos remanescentes em estádio avançado de sucessão, faz com que toda a região seja interpretada como abrangida especialmente pela Floresta Ombrófila Mista (Jarenkow \& Budke 2009).

Numa escala regional, percebe-se que estas florestas estão fortemente associadas a um gradiente climático, principalmente à temperatura (Oliveira-Filho et al. 2006). Porém, numa escala local, onde não se perceba a presença de variáveis limitantes ao desenvolvimento da vegetação, é provável que a distribuição das espécies esteja associada às interações e processos gerados majoritariamente pela própria dinâmica interespecífica, em especial, à dinâmica de mosaicos (Glenn-Levin \& van der Maarel 1992). Neste sentido, espera-se que as espécies apresentem distribuição espacial agrupada e que os agrupamentos presentes sejam perceptíveis em pequenas escalas, tornando-se aleatórios ou até mesmo segregados (dissociação) em escalas maiores.

Partindo-se desta premissa, pretendeu-se analisar os padrões espaciais e grupos ecológicos de espécies arbóreas e avaliar a interferência destes padrões sobre métricas de riqueza e diversidade, em um remanescente florestal de transição entre estas formações florestais (Floresta Ombrófila Mista e Floresta Estacional), localizado na região Alto Uruguai, no sul do Brasil. Considerando que a área encontra-se em estádio avançado de sucessão, buscou-se verificar se: i) grupos ecológicos de dispersão, necessidades de luz para germinação e estratificação vertical refletem o estádio sucessional do remanescente em questão; ii) ocorrem associações entre a distribuição das espécies com maior abundância no remanescente; iii) os agrupamentos das espécies mais abundantes interferem na riqueza específica e equabilidade ao longo da área amostrada.

\section{Material e métodos}

\section{Caracterização da área de estudo}

$\mathrm{O}$ estudo foi desenvolvido num remanescente florestal de transição entre Floresta Estacional Semidecídua e Floresta Ombrófila Mista (Oliveira-Filho et al. 2006) com aproximadamente 877,5 ha, localizado na Microbacia do Córrego Divisa, município de Faxinalzinho, região Alto Uruguai no estado do Rio Grande do Sul. O remanescente estudado possui superfície sob as coordenadas S $27^{\circ} 20^{\circ}$ $40,5^{\prime \prime} ; 27^{\circ} 26^{\prime} 36^{\prime \prime}$ e W $52^{\circ} 40^{\prime} 32,2^{\prime \prime} ; 52^{\circ} 44^{\prime} 38^{\prime \prime}$, com altitude em torno de 615 metros (Leyser et al. 2009). O clima da 
região é classificado como subtropical úmido do tipo Cfa, com chuvas bem distribuídas ao longo do ano e temperatura média do mês mais frio superior a $18^{\circ} \mathrm{C}$, segundo a classificação de Köppen (1948). Dados climáticos coletados na estação meteorológica de Erechim, instalada a $750 \mathrm{~m}$ acima do nível do mar para o período de 1976 a 2005 sugerem que o clima da região deve se enquadrar no limite entre Cfa e $\mathrm{Cfb}$, com temperatura média anual de $17,6^{\circ} \mathrm{C}$, mínima de $12,7^{\circ} \mathrm{C}$ no mês de junho e máxima de $25,5^{\circ} \mathrm{C}$ no mês de janeiro. As chuvas são bem distribuídas durante o ano e atingem precipitação média acima de $1.900 \mathrm{~mm}$ por ano (Bernardi \& Budke 2010).

\section{Desenho amostral e coleta dos dados}

O levantamento foi realizado pelo método de parcelas (Mueller-Dombois \& Ellenberg 1974), num total de 100 unidades amostrais de $10 \times 10 \mathrm{~m}$, dispostas em uma grade contígua. Todos os indivíduos com perímetro à altura do peito (PAP) $\geq 15 \mathrm{~cm}$ foram amostrados e tiveram suas alturas estimadas por comparação a uma tesoura de alta poda de $13 \mathrm{~m}$. O material fértil coletado foi etiquetado, identificado e herborizado no Laboratório de Sistemática e Ecologia Vegetal - ECOSSIS, da Universidade Regional Integrada do Alto Uruguai e das Missões - URI, Campus de Erechim e posteriormente incorporado ao acervo do Herbário Padre Balduíno Rambo - HPBR. A nomenclatura das espécies seguiu Sobral et al. (2006).

\section{Análise dos dados}

Inicialmente, foram obtidos os parâmetros absolutos de densidade, freqüência e dominância. Quanto aos grupos ecológicos, a classificação das estratégias de dispersão seguiu a proposta de Van der Pijl (1982), identificando as espécies como zoocóricas, anemocóricas ou autocóricas, de acordo com a morfologia dos diásporos. Quanto à estratificação vertical, os indivíduos foram classificados nas classes: sub-bosque (indivíduos adultos de pequeno porte, com altura máximo em torno de oito metros), dossel (indivíduos adultos de grande porte, formando a cobertura superior da floresta) e, emergente (árvores com copas acima do dossel) (Oliveira-Filho et al. 1994). Seguindo a proposta de Swaine e Whitmore (1988), as espécies foram classificadas quanto à necessidade de luz para o estabelecimento e desenvolvimento inicial em tolerantes à sombra, demandantes de luz e pioneiras, de acordo com a literatura (Budke et al. 2007, 2008) e observação dos próprios autores. Proporções de espécies e indivíduos nas diferentes categorias ecológicas foram comparadas entre si por testes de Qui-quadrado (Zar 1996).

A descrição dos padrões espaciais das espécies com densidade $\geq 20$ ind.ha ${ }^{-1}$ foi realizada por meio de análises de correlogramas, utilizando o índice I de Moran (Legendre \& Fortin 1989). Este índice mede a autocorrelação espacial entre duas unidades amostrais, tendo como base a distância métrica entre elas e as abundâncias da espécie em questão. Pode-se então avaliar a presença de autocorrelação positiva ou negativa entre as unidades amostrais, a partir de diversas classes de distâncias, gerando assim um correlograma para a espécie (Rosenberg \& Anderson 2011). No presente estudo, foram definidas 10 classes de distância com intervalos crescentes de 10 metros, valor correspondente à largura mínima entre unidades amostrais (Costa \& Santos 2011). Cada correlograma gerou respectivos valores de índice I de Moran, de acordo com a classe de distância analisada, variando de -1 a 1 , sendo cada valor verificado quanto à significância por meio da correção de Bonferroni para comparações múltiplas (Legendre \& Legendre 1998; Rosenberg \& Anderson 2011). Neste sentido, valores próximos a zero (não significativos) representaram a hipótese nula de aleatoriedade na distribuição da abundância da espécie. Os correlogramas foram gerados pelo programa Passage 2.0 (Rosenberg \& Anderson 2011).

Por outro lado, as espécies tiveram sua distribuição espacial analisada por meio do índice de agregação - Ia (Perry 1998). Este índice tem como base a quantificação do esforço total, medido em distância, que os indivíduos amostrados precisariam utilizar para formar arranjos extremos, onde eles pudessem estar tão agregados ou dispersos quanto possível (Perry 1998). Para tanto, cada unidade amostral recebeu uma descrição da posição espacial por meio de coordenadas $(x ; y)$, mapeadas a partir de uma unidade amostral inicial. Quando Ia $>1$, a distribuição da espécie foi considerada agrupada, e quando Ia $<-1$, a distribuição da espécie foi considerada regular. Da mesma, forma valores de agregação negativos indicam que em determinada posição a espécie não ocorreu (lacuna), complementando a análise do padrão (Perry et al. 1999). Um teste de aleatorização foi empregado, no qual os valores observado são permutados entre as unidades amostrais para se avaliar a significância dos valores encontrados (Perry et al. 1998) e mapas de distribuição das espécies foram gerados pela técnica de kriging por meio do aplicativo Surfer 8.0 (Golden Software 2002).

Os índices obtidos pelos correlogramas em cada classe de distância foram finalmente comparados aos gráficos de superfície gerados a partir da análise de distribuição espacial, de modo a observar as escalas de agregação, segregação e aleatoriedade que ocorreram entre unidades amostrais (Costa \& Santos 2011), permitindo uma análise mais acurada da distribuição de abundâncias em determinadas escalas (McIntire \& Fajardo 2009).

As distribuições das espécies foram comparadas aos pares objetivando-se identificar padrões de co-ocorrência entre espécies, por meio do teste de associação - Im, o qual verifica a presença de associações ou dissociações entre as espécies (Perry et al. 1998). Neste caso, a hipótese nula testada foi de ausência de dissociações ou associações entre espécies. Após a análise de distribuição espacial e de associação entre espécies, foram realizadas observações complementares, com o intuito de verificar os possíveis impactos de agrupamentos das espécies com maior densidade sobre parâmetros de riqueza e equabilidade. Assim, foi aplicado 
o teste de correlação de Spearmann entre a abundância de cada espécie e os respectivos parâmetros de riqueza específica e equabilidade de Pielou, obtidos por unidade amostral. A avaliação da distribuição espacial e os testes de associação foram obtidos com o programa SADIEShell (Perry et al. 1998).

\section{Resultados}

Foram amostrados 1.215 indivíduos distribuídos em 74 espécies de 54 gêneros, pertencentes a 32 famílias botânicas (Tab. 1). A família com o maior número de espécies amostradas foi Fabaceae (10), seguida de Myrtaceae (7) e Lauraceae (6). Três famílias contribuíram com cerca de $50 \%$ do número total de indivíduos, destacando-se a família Salicaceae, com $25 \%$ do total de indivíduos presentes na área amostrada, além de Lauraceae e Meliaceae (Tab. 1). As espécies com maiores valores de densidade absoluta (DA) foram Casearia sylvestris (223), Ocotea diospyrifolia (137), Cabralea canjerana (108) e Casearia decandra (61), sendo correspondentes a $44 \%$ do total de indivíduos amostrados. As espécies que apresentaram maior valor de freqüência absoluta foram Casearia silvestris (77), Ocotea diospyrifolia e Cabralea canjerana (61). Todas as outras espécies ocorreram em baixas freqüências, sendo que $92 \%$ das espécies amostradas estão presentes em menos de $20 \%$ das unidades amostrais (Tab. 1). Os maiores valores para área basal foram de Ocotea diospyrifolia, Casearia sylvestris, Luehea divaricata, Nectandra lanceolata e Cryptocarya moschata, devido ao elevado número de indivíduos ou ao grande porte de alguns espécimes. O valor de área basal total foi de $35,1 \mathrm{~m}^{2} \cdot \mathrm{ha}^{-1}$.

Constatou-se que $50 \%$ dos indivíduos estão entre cinco e $10 \mathrm{~cm}$ de diâmetro, sugerindo um grande número de árvores em regeneração. Aproximadamente $27 \%$ dos indivíduos amostrados têm entre 11 e $20 \mathrm{~cm}$ de diâmetro, ocorrendo uma redução no número de indivíduos das classes seguintes (Fig. 1A).

Quanto à distribuição em classes de altura, cerca de 80\% dos indivíduos apresentaram alturas iguais ou inferiores à classe de seis a nove metros (Fig. 1B), revelando que a maior parte dos indivíduos adultos apresentou porte médio ou são característicos de sub-bosque. $\mathrm{O}$ mosaico florestal não apresentou estratificação nítida, ocorrendo um adensamento acentuado de indivíduos nas classes de alturas menores, sem diferenças drásticas entre os números obtidos para as demais classes (Fig. 1B).

Avaliando-se os parâmetros necessários para o desenvolvimento e estabelecimento inicial, grande parte dos indivíduos amostrados é demandante de luz, assim como a maioria das espécies, com diferenças significativas entre as distintas classes (Tab. 2). Analisando as estratégias de dispersão, foi observado que a maioria dos indivíduos apresentou características para dispersão por animais, seguidos por indivíduos anemocóricos e um número reduzido de indivíduos autocóricos (Tab. 2). Quando relacionadas às estratégias
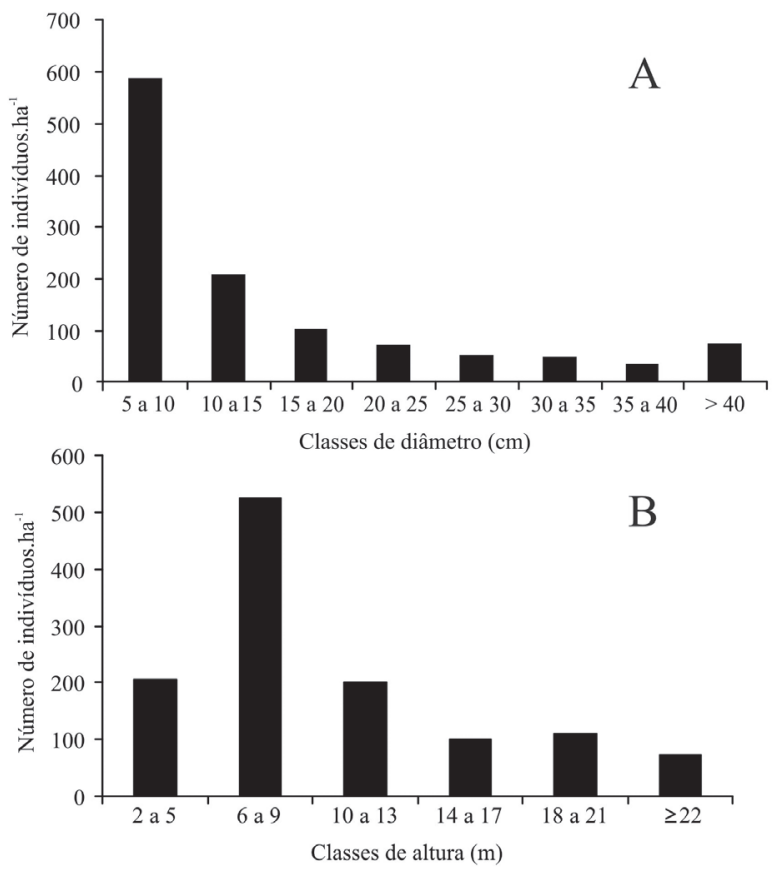

Figura 1. Distribuição de indivíduos em classes de diâmetro (A) e altura (B) dos indivíduos arbóreos amostrados em uma floresta subtropical no sul do Brasil.

de dispersão com o porte dos indivíduos, verificou-se que $85 \%$ dos indivíduos emergentes são zoocóricos, enquanto que $13 \%$ dos indivíduos são anemocóricos e apenas $1 \%$ dos indivíduos autocóricos (Tab. 1). A proporção de indivíduos classificados como formadores do dossel e emergentes apresentaram padrão semelhante, com $77 \%$ de indivíduos zoocóricos, $20 \%$ anemocóricos e $3 \%$ autocóricos (Tab. 1). Por outro lado, o sub-bosque destacou-se pela proporção elevada (80\%) de indivíduos autocóricos. Este resultado foi obtido apenas quando considerado o número de indivíduos, havendo uma alta densidade de Gymnanthes concolor, que elevou a proporção da estratégia de dispersão autocórica entre as árvores de baixa estatura.

A análise dos padrões espaciais das espécies evidenciou um predomínio de autocorrelação espacial positiva (índices I de Moran positivos) entre as duas primeiras classes de distância, com picos de agregação entre 10 e 20 metros de distância (Fig. 2). Nas classes de distância intermediárias (30 a $60 \mathrm{~m}$ ), a ausência de valores significativos (positivos ou negativos) indicou que as espécies apresentaram distribuição predominantemente aleatória. Finalmente, nas classes de distância maiores (acima de $70 \mathrm{~m}$ ), observaram-se várias espécies com valores de I de Moran negativos, indicando espécies com segregação espacial, com exceção de Banara tomentosa e Lonchocarpus campestris, as quais apresentaram o padrão inverso nas maiores classes (Fig. $2 \mathrm{~A})$. Dentre as espécies que se destacaram com pequenos agrupamentos, Sorocea bonplandii, Ilex brevicuspis e Cryptocarya moschata apresentaram os maiores valores do índice I de Moran (Tab. 3). Por outro lado, as espécies 
Tabela 1. Espécies arbóreas registradas em uma floresta subtropical no sul do Brasil, em ordem decrescente de valor de importância das famílias. $\mathrm{CE}=$ características ecológicas, onde TS = tolerante à sombra; $\mathrm{DL}=$ dependente de luz; $\mathrm{P}=$ espécie pioneira; $\mathrm{M}$ = indivíduos de médio porte; $\mathrm{S}=$ sub-bosque; $\mathrm{E}=$ emergentes; $\mathrm{Zoo}=$ zoocoria; Ane = anemocoria e Aut = autocoria. $\mathrm{DA}=$ densidade absoluta $\left(\right.$ ind.ha $\left.\mathrm{a}^{-1}\right) ; \mathrm{DoA}=$ dominância absoluta $\left(\mathrm{m}^{2} \cdot \mathrm{ha}^{-1}\right) ; \mathrm{FA}=$ freqüência absoluta.

\begin{tabular}{|c|c|c|c|c|}
\hline Famílias/Espécies & $\mathrm{CE}$ & DA & DoA & $\mathrm{FA}$ \\
\hline \multicolumn{5}{|l|}{ LAURACEAE } \\
\hline Cryptocarya moschata Nees \& Mart. ex Nees & TS-E-Zoo & 38 & 2,06 & 29 \\
\hline Nectandra lanceolata Nees & DL-E-Zoo & 20 & 2,32 & 18 \\
\hline Nectandra megapotamica (Spreng.) Mez & DL-M-Zoo & 15 & 0,98 & 9 \\
\hline Ocotea diospyrifolia (Meisn.) Mez & DL-E-Zoo & 137 & 10,96 & 61 \\
\hline Ocotea puberula (Rich.) Nees & DL-E-Zoo & 2 & 0,17 & 2 \\
\hline Ocotea pulchella (Nees) Mez & DL-M-Zoo & 5 & 0,28 & 5 \\
\hline \multicolumn{5}{|l|}{ SALICACEAE } \\
\hline Banara tomentosa Clos & DL-M-Zoo & 29 & 0,20 & 14 \\
\hline Casearia decandra Jacq. & TS-M-Zoo & 61 & 0,61 & 29 \\
\hline Casearia sylvestris Swartz & DL-M-Zoo & 223 & 2,44 & 77 \\
\hline \multicolumn{5}{|l|}{ MELIACEAE } \\
\hline Cabralea canjerana (Vell.) Mart. & DL-E-Zoo & 108 & 0,82 & 61 \\
\hline Cedrela fissilis Vell. & DL-E-Ane & 4 & 0,73 & 4 \\
\hline \multicolumn{5}{|l|}{ FABACEAE } \\
\hline Albizia edwallii (Hoehne) Barneby \& J. Grimes & DL-E-Ane & 1 & 0,06 & 1 \\
\hline Apuleia leiocarpa (Vogel) J.F. Macbr. & DL-E-Ane & 10 & 0,47 & 10 \\
\hline Machaerium paraguariense Hassler & DL-M-Ane & 2 & 0,01 & 2 \\
\hline Parapiptadenia rigida (Benth.) Brenan & DL-E-Aut & 2 & 0,02 & 2 \\
\hline Dalbergia frutescens (Vell.) Britton & DL-M-Ane & 6 & 0,1 & 5 \\
\hline Ateleia glazioviana Baill. & P-M-Ane & 15 & 0,88 & 11 \\
\hline Calliandra foliolosa Benth. & TS-S-Aut & 9 & 0,03 & 6 \\
\hline Inga marginata Willd. & DL-M-Zoo & 2 & 0,15 & 2 \\
\hline Lonchocarpus campestris Mart. ex Benth. & DL-M-Ane & 22 & 0,60 & 16 \\
\hline Myrocarpus frondosus Allemão & TS-E-Ane & 20 & 0,37 & 10 \\
\hline \multicolumn{5}{|l|}{ MALVACEAE } \\
\hline Luehea divaricata Mart. \& Zucc. & DL-M-Ane & 29 & 2,37 & 26 \\
\hline \multicolumn{5}{|l|}{ MYRTACEAE } \\
\hline Campomanesia guazumifolia (Cambess.) O.Berg & TS-M-Zoo & 20 & 0,25 & 24 \\
\hline Campomanesia xanthocarpa O.Berg. & TS-M-Zoo & 6 & 0,09 & 6 \\
\hline Eugenia hiemalis Cambess. & DL-M-Zoo & 3 & 0,01 & 3 \\
\hline Eugenia involucrata DC. & DL-M-Zoo & 1 & 0,01 & 1 \\
\hline Eugenia pyriformis Cambess. & TS-M-Zoo & 4 & 0,20 & 3 \\
\hline Myrcia hebepetala DC. & TS-M-Zoo & 10 & & 7 \\
\hline Myrcia bombycina (O.Berg.) Nied. & DL-M-Zoo & 1 & 0,01 & 1 \\
\hline \multicolumn{5}{|l|}{ EUPHORBIACEAE } \\
\hline Manihot grahamii Hook. & DL-S-Aut & 1 & 0,01 & 1 \\
\hline Sapium glandulosum (L.) Morong & DL-M-Aut & 1 & 0,01 & 1 \\
\hline Sebastiania brasiliensis Spreng. & DL-M-Aut & 6 & 0,02 & 4 \\
\hline Sebastiania commersoniana (Baill.) L.B. Sm. \& Downs & DL-M-Aut & 10 & 0,23 & 8 \\
\hline Gymnanthes concolor Spreng. & TS-S-Aut & 41 & 0,38 & 18 \\
\hline \multicolumn{5}{|l|}{ SAPINDACEAE } \\
\hline Allophylus puberulus (Cambess.) Radlk. & DL-M-Zoo & 9 & 0,14 & 9 \\
\hline Cupania vernalis Cambess. & DL-E-Zoo & 22 & 0,21 & 16 \\
\hline Diatenopteryx sorbifolia Radlk. & TS-E-Zoo & 2 & 0,19 & 2 \\
\hline Matayba elaeagnoides Radlk. & DL-E-Zoo & 7 & 0,59 & 7 \\
\hline \multicolumn{5}{|l|}{ ANNONACEAE } \\
\hline Annona rugulosa (Schltdl.) H. Rainer & DL-M-Zoo & 8 & 0,04 & 6 \\
\hline Annona neosalicifolia $\mathrm{H}$. Rainer & DL-M-Zoo & 35 & 0,53 & 29 \\
\hline \multicolumn{5}{|l|}{ AQUIFOLIACEAE } \\
\hline Ilex brevicuspis Reissek & TS-M-Zoo & 20 & 0,69 & 12 \\
\hline Ilex paraguariensis A. St. Hil. & DL-M-Zoo & 15 & 0,03 & 13 \\
\hline
\end{tabular}


Tabela 1. Continuação.

\begin{tabular}{|c|c|c|c|c|}
\hline Famílias/Espécies & $\mathrm{CE}$ & $\mathrm{DA}$ & DoA & FA \\
\hline \multicolumn{5}{|l|}{ BORAGINACEAE } \\
\hline Cordia americana (L.) Gottschling \& J. E. Mill. & DL-M-Ane & 20 & 0,98 & 16 \\
\hline Cordia trichotoma (Vell.) Arráb. Ex Steud. & DL-M-Ane & 2 & 0,10 & 2 \\
\hline \multicolumn{5}{|l|}{ RUBIACEAE } \\
\hline Chomelia obtusa Cham. \& Schltdl. & DL-S-Zoo & 6 & 0,02 & 4 \\
\hline Randia ferox (Cham. \& Schltdl.) DC. & TS-M-Zoo & 10 & 0,27 & 10 \\
\hline Rudgea jasminoides (Cham.) Müll. Arg. & TS-S-Zoo & 11 & 0,07 & 10 \\
\hline \multicolumn{5}{|l|}{ MORACEAE } \\
\hline Ficus luschnathiana (Miq.) Miq. & DL-E-Zoo & 2 & 0,01 & 2 \\
\hline Sorocea bonplandii (Baill.) W.C. Burger et al. & TS-S-Zoo & 24 & 0,16 & 17 \\
\hline \multicolumn{5}{|l|}{ RUTACEAE } \\
\hline Balfourodendron riedelianum (Engl.) Engl. & DL-M-Ane & 5 & 0,04 & 4 \\
\hline Pilocarpus pennatifolius Lem. & TS-S-Zoo & 4 & 0,02 & 3 \\
\hline Zanthoxylum caribaeum Lam. & DL-M-Zoo & 5 & 0,02 & 3 \\
\hline Helietta apiculata Benth. & DL-M-Zoo & 8 & 0,10 & 7 \\
\hline \multicolumn{5}{|l|}{ RHAMNACEAE } \\
\hline Hovenia dulcis Thunb. & DL-M-Zoo & 4 & 0,05 & 2 \\
\hline \multicolumn{5}{|l|}{ LAMIACEAE } \\
\hline Vitex megapotamica (Spreng.) Moldenke & DL-M-Zoo & 2 & 0,07 & 2 \\
\hline \multicolumn{5}{|l|}{ BIGNONIACEAE } \\
\hline Jacaranda micrantha Cham. & DL-E-Ane & 15 & 0,19 & 14 \\
\hline \multicolumn{5}{|l|}{ APOCYNACEAE } \\
\hline Aspidosperma australe Müll.Arg. & TS-M-Ane & 18 & 0,08 & 14 \\
\hline \multicolumn{5}{|l|}{ CUNONIACEAE } \\
\hline Lamanonia ternata Vell. & TS-M-Ane & 14 & 0,24 & 11 \\
\hline \multicolumn{5}{|l|}{ ASTERACEAE } \\
\hline Piptocarpha angustifolia Dusén ex Malme & DL-M-Ane & 3 & 0,36 & 2 \\
\hline Vernonia discolor (Spreng.) Less. & DL-M-Ane & 7 & 0,13 & 6 \\
\hline \multicolumn{5}{|l|}{ ARAUCARIACEAE } \\
\hline Araucaria angustifolia (Bertol.) Kuntze & DL-E-Zoo & 5 & 0,78 & 5 \\
\hline \multicolumn{5}{|l|}{ LOGANIACEAE } \\
\hline Strychnos brasiliensis (Spreng.) Mart. & DL-M-Zoo & 13 & 0,08 & 9 \\
\hline \multicolumn{5}{|l|}{ PRIMULACEAE } \\
\hline Myrsine umbellata Mart. & DL-M-Zoo & 12 & 0,09 & 9 \\
\hline \multicolumn{5}{|l|}{ SAPOTACEAE } \\
\hline Chrysophyllum gonocarpum (Mart. \& Eichler) Engl. & TS-M-Zoo & 7 & 0,03 & 6 \\
\hline Chrysophyllum marginatum (Hook. \& Arn.) Radlk. & DL-M-Zoo & 3 & 0,04 & 3 \\
\hline \multicolumn{5}{|l|}{ STYRACACEAE } \\
\hline Styrax leprosus Hook. \& Arn. & DL-M-Zoo & 5 & 0,24 & 5 \\
\hline \multicolumn{5}{|l|}{ ERYTHROXYLACEAE } \\
\hline Erythroxylum deciduum A. St.- Hil. & DL-M-Zoo & 2 & 0,07 & 2 \\
\hline Erythroxylum myrsinites Mart. & TS-S-Zoo & 5 & 0,02 & 4 \\
\hline \multicolumn{5}{|l|}{ CARDIOPTERIDACEAE } \\
\hline Citronella paniculata (Mart.) R.A. Howard & DL-M-Zoo & 5 & 0,04 & 4 \\
\hline \multicolumn{5}{|l|}{ ROSACEAE } \\
\hline Prunus myrtifolia (L.) Urb. & DL-M-Zoo & 3 & 0,10 & 3 \\
\hline \multicolumn{5}{|l|}{ CANELLACEAE } \\
\hline Cinnamodendron dinisii Schwancke & TS-M-Zoo & 4 & 0,02 & 3 \\
\hline POLYGONACEAE & & & & \\
\hline Ruprechtia laxiflora Meisn. & DL-E-Ane & 2 & 0,01 & 2 \\
\hline URTICACEAE & & & & \\
\hline Urera baccifera (L) Gaudich. & DL-S-Zoo & 2 & 0,01 & 2 \\
\hline CELASTRACEAE & & & & \\
\hline Maytenus aquifolia Mart. & TS-S-Zoo & 1 & 0,01 & 1 \\
\hline
\end{tabular}


Casearia decandra, Campomanesia guazumifolia e Luehea divaricata destacaram-se pelos altos índices de segregação espacial nas maiores classes de distância (valores de I de Moran negativos) (Tab. 3) (Fig. 2A, B).

Quanto à análise de distribuição espacial, verificou-se que 14 das 17 espécies analisadas apresentaram distribuição agrupada, com indivíduos geralmente concentrados em um determinado ponto da área e agrupamentos de menor densidade bem distribuídos (Fig. 3, 4 e 5), corroborando os padrões observados pelos correlogramas. Os valores mais significativos de agregação foram de Luehea divaricata, Cryptocarya moschata e Casearia decandra, evidenciando a presença de pelo menos um agrupamento com elevada densidade de indivíduos destas espécies (Tab. 4). De modo geral, as espécies com os maiores valores de agregação foram formadas por apenas um grupo de elevada densidade de indivíduos, fato evidenciado pelo elevado valor médio do índice de agregação (Tab. 4), ou então, pela elevada segregação indicada pelos índices $v j$, correspondentes às lacunas de ocorrência de uma determinada espécie (Tab. 4). Por outro lado, ficou evidente por meio da observação dos mapas de distribuição das espécies e pelos correlogramas que Annona neosalicifolia é uma exceção, apresentando-se em diversos agrupamentos de menor densidade (Fig. 3-B). Com exceção de Cordia americana, Luehea divaricata e Lonchocarpus campestris as espécies com índices significativos de agregação são classificadas como zoocóricas (Tab. 4).

Não houve relação entre os agrupamentos das espécies e a abundância de indivíduos em cada unidade amostral $(r=-0,02 ; p=0,93)$. Das 14 espécies com distribuição agrupada, dez delas apresentaram correlação positiva com riqueza de espécies por unidade amostral (Tab. 4), em especial, a riqueza específica mostrou-se altamente correlacionada às espécies Lonchocarpus campestris e Sorocea bonplandii. Quanto à relação entre a distribuição espacial das espécies e a equabilidade, foi observada uma relação negativa com os agrupamentos de Casearia sylvestris e Ocotea diospyrifolia e relação positiva com Lonchocarpus campestris e Cryptocarya moschata (Tab. 4).

Quanto às análises de associação (Tab. 5), foram observados sobreposições e deslocamentos, em especial, entre Gymnanthes concolor e Sorocea bonplandii e entre Cabralea canjerana e Ilex brevicuspis, cujos agrupamentos mostraram-se fortemente associados $(p<0,0001)$. De forma geral, quando houve relação positiva entre os adensamentos, esta se deu de maneira muito significativa, indicando níveis altos de co-ocorrência entre as espécies. Por outro lado, relações negativas foram menos frequentes e em geral, de fraca dissociação entre espécies (Tab. 5).

\section{Discussão}

A grande riqueza de Fabaceae e Myrtaceae tem sido considerada um padrão comum em florestas estacionais no Brasil (Jarenkow \& Waechter 2001; Budke et al. 2004;
Oliveira-Filho et al. 2006). Na porção meridional do país, Myrtaceae é considerada uma família com elevada riqueza em praticamente todas as formações florestais, embora se tenha observado um aumento gradativo na riqueza de espécies da família Fabaceae ao se distanciar continuamente do litoral (Jarenkow \& Budke 2009). Por outro lado, nas porções mais elevadas do planalto sul-brasileiro, a distribuição das espécies é sujeita às variações de temperatura e precipitação atmosférica, onde a Araucaria angustifolia (Bertol.) O.Kuntze imprime um caráter fitofisionômico distinto, corroborando para a criação de classificações de natureza descritiva, como a Floresta Ombrófila Mista (Jarenkow \& Budke 2009). Na área do presente estudo, situada a cerca de $600 \mathrm{~m}$ de altitude, pode-se perceber a ocorrência de espécies características de florestas estacionais, como Balfourodendron riedelianum, Apuleia leiocarpa, Albizia edwalli, Calliandra foliolosa, Allophylus puberulus, bem como, de espécies comuns às florestas com Araucária,
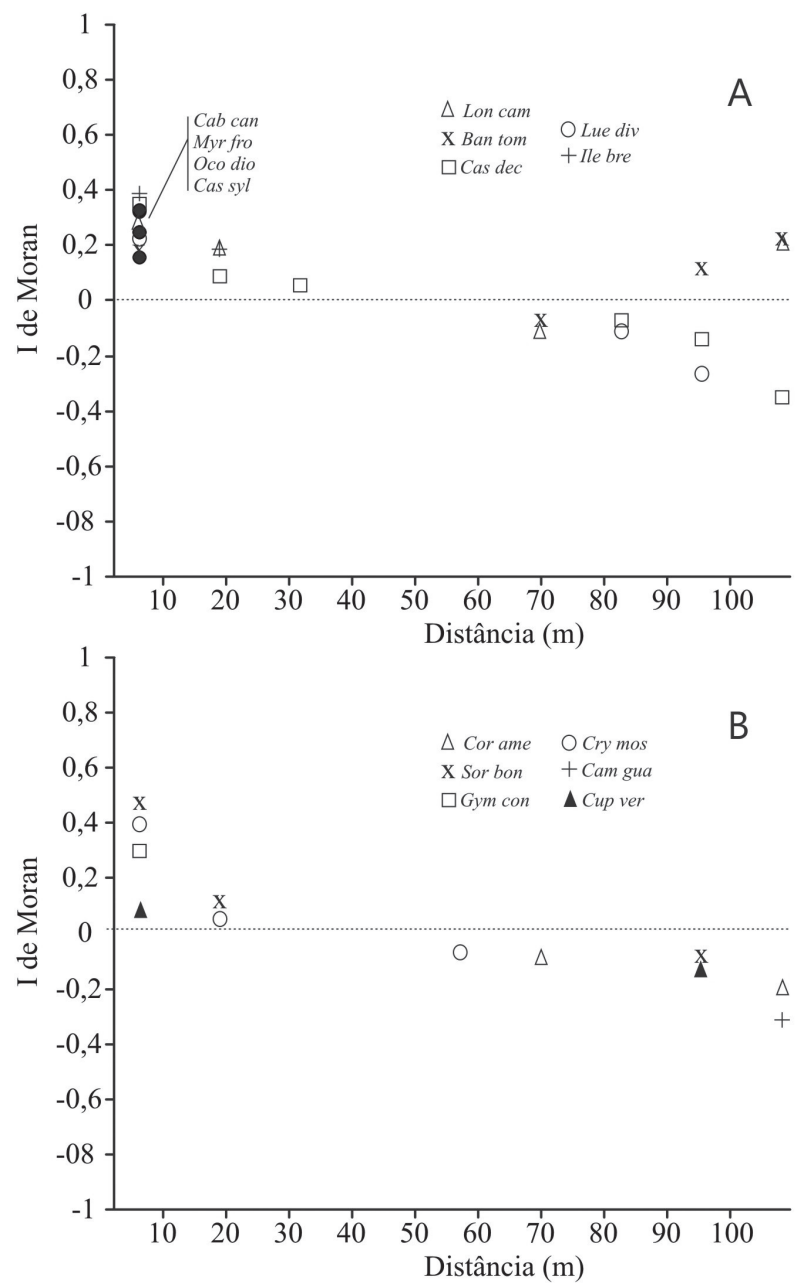

Figura 2. Correlogramas e índices I de Moran significativos das espécies arbóreas com abundância $\geq 20$ indivíduos amostrados em uma floresta subtropical no sul do Brasil. Os acrônimos representam as três primeiras letras do gênero e epíteto específico. 
Tabela 2. Proporção de espécies e indivíduos classificados quanto às estratégias de dispersão, necessidades de luz para o estabelecimento inicial e porte dos indivíduos amostrados em um remanescente de floresta subtropical no sul do Brasil.

\begin{tabular}{|c|c|c|c|c|}
\hline Categoria ecológica & $\%$ de Spp & $\chi^{2}$ & $\%$ de Ind & $x^{2}$ \\
\hline \multicolumn{5}{|c|}{ Estratégias de dispersão } \\
\hline Zoocóricas & 62 & & 76 & \\
\hline Anemocóricas & 30 & $50,96^{*}$ & 17 & $91,28^{\circ}$ \\
\hline Autocóricas & 8 & & 7 & \\
\hline \multicolumn{5}{|l|}{ Necessidades de luz } \\
\hline Tolerantes à Sombra & 28 & & 28 & \\
\hline Dependentes de Luz & 70 & $70,64^{*}$ & 71 & $74,78^{\circ}$ \\
\hline Pioneiras & 2 & & 1 & \\
\hline \multicolumn{5}{|l|}{ Estratificação/porte } \\
\hline Sub-bosque & 13 & & 9 & \\
\hline Dossel & 64 & $43,82^{*}$ & 59 & $37,58^{\circ}$ \\
\hline Emergente & 23 & & 32 & \\
\hline
\end{tabular}

Tabela 3. Índices I de Moran (mínimos e máximos) de espécies com abundância $\geq 20$ indivíduos amostrados em uma floresta subtropical no sul do Brasil. $\mathrm{N}$ = número de indivíduos amostrados.

\begin{tabular}{|c|c|c|c|c|}
\hline Espécie & $\mathrm{N}$ & I Moran mín & I Moran máx & $p$ \\
\hline Casearia sylvestris & 223 & 0,01 & 0,33 & $<0,01$ \\
\hline Ocotea diospyrifolia & 137 & 0,01 & 0,24 & $<0,01$ \\
\hline Cabralea canjerana & 108 & $-0,01$ & 0,24 & $<0,01$ \\
\hline Casearia decandra & 61 & $-0,04$ & $-0,33$ & $<0,01$ \\
\hline Gymnantes concolor & 41 & 0,01 & 0,32 & $<0,01$ \\
\hline Cryptocarya moschata & 38 & $-0,01$ & 0,33 & $<0,01$ \\
\hline Annona neosalicifolia & 35 & 0,01 & $-0,06$ & 0,37 \\
\hline Banara tomentosa & 29 & $-0,01$ & 0,22 & 0,03 \\
\hline Luehea divaricata & 29 & $-0,01$ & $-0,26$ & $<0,01$ \\
\hline Campomanesia guazumifolia & 24 & $-0,01$ & $-0,31$ & 0,02 \\
\hline Sorocea bonplandii & 24 & 0,01 & 0,42 & $<0,01$ \\
\hline Cupania vernalis & 22 & $-0,01$ & 0,13 & 0,25 \\
\hline Lonchocarpus campestris & 22 & 0,02 & 0,26 & $<0,01$ \\
\hline Cordia americana & 20 & 0,1 & $-0,21$ & 0,08 \\
\hline Ilex brevicuspis & 20 & $-0,31$ & 0,38 & $<0,01$ \\
\hline Myrocarpus frondosus & 20 & $-0,01$ & 0,15 & 0,08 \\
\hline Nectandra lanceolata & 20 & $-0,01$ & $-0,12$ & 0,15 \\
\hline
\end{tabular}

como Piptocarpha angustifolia, Vernonanthura discolor, Cinnamodendron dinisii e Myrcia bombycina, numa clara transição entre estas formações florestais. Conforme discutido por M.A.Mélo (dados não publicados) muitas destas espécies, em especial aquelas de grande porte, foram sendo aproveitadas para fins diversos, inclusive para exportação, além da própria expansão agrícola, o que acabou modificando a fisionomia da região Alto Uruguai e diminuindo a ocorrência de grandes exemplares de espécies emergentes. Desta forma, pode-se sugerir que as florestas localizadas nesta região, entre cotas de 400 e 600 metros de altitude constituem-se numa transição entre a Floresta Estacional Semidecídua e a Floresta Ombrófila Mista.
Embora a densidade absoluta da área tenha sido comparável a outros trabalhos realizados em florestas estacionais (Jarenkow \& Waechter 2001; Lindenmaier \& Budke 2006), foi observada uma área basal relativamente baixa, se comparada a outros trabalhos em florestas com Araucária (Jarenkow \& Budke 2009), o que pode sinalizar que tenham ocorrido cortes seletivos no passado, provavelmente modificando a estrutura florestal da área. Atualmente, o remanescente possui a maior parte de seus indivíduos nas primeiras classes de altura e diâmetro, as quais, embora influenciadas por algumas espécies de sub-bosque de elevada densidade, concentram grande parte dos indivíduos em fase de regeneração. Logo, pode-se esperar que a área basal 

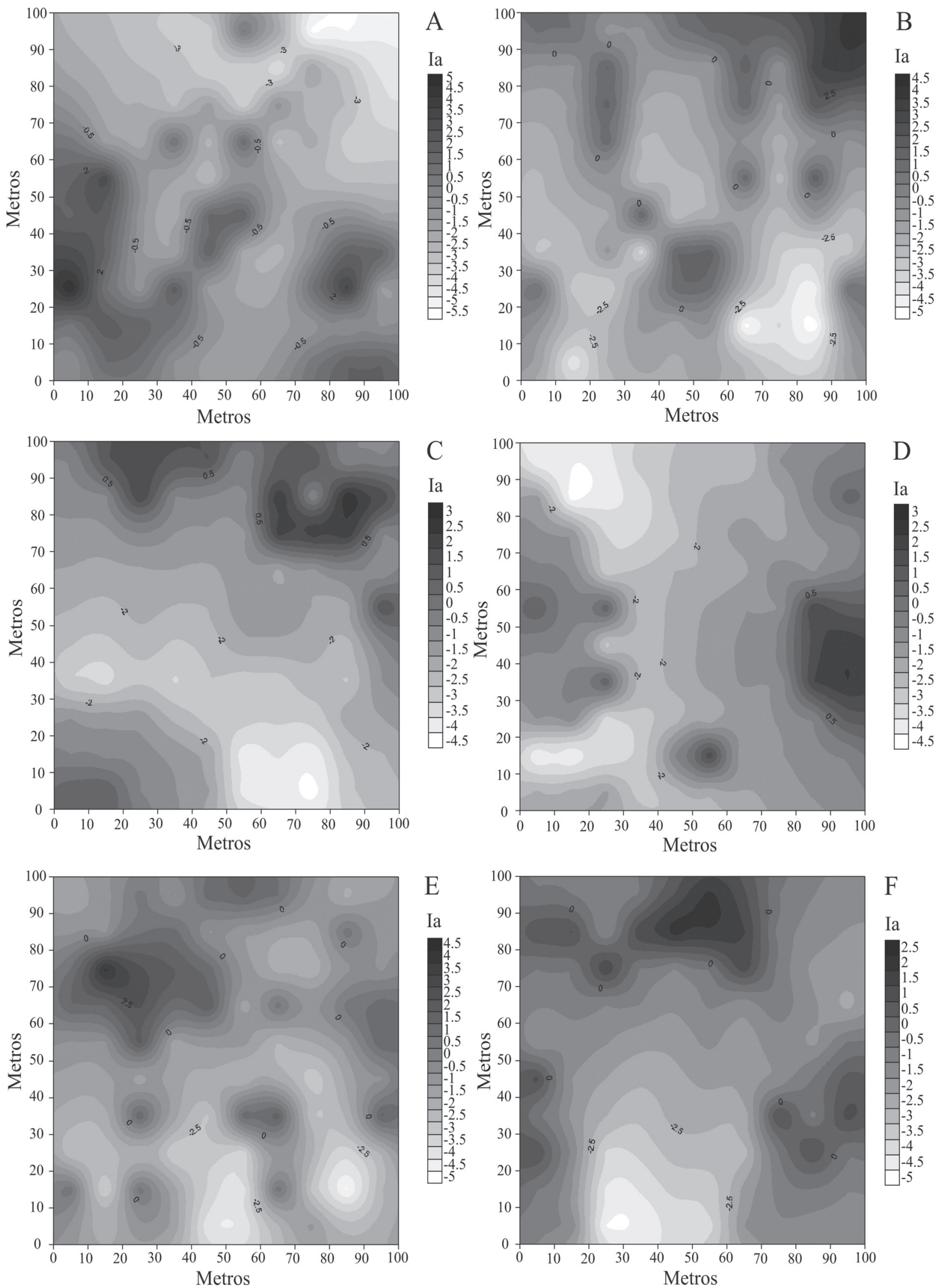

Figura 3. Diagramas de superfície das espécies com abundância $\geq 20$ indivíduos amostrados em uma floresta subtropical no sul do Brasil. A) Casearia decandra; B) Luehea divaricata; C) Lonchocarpus campestris; D) Ilex brevicuspis; E) Cryptocarya moschata; F) Sorocea bonplandii. 

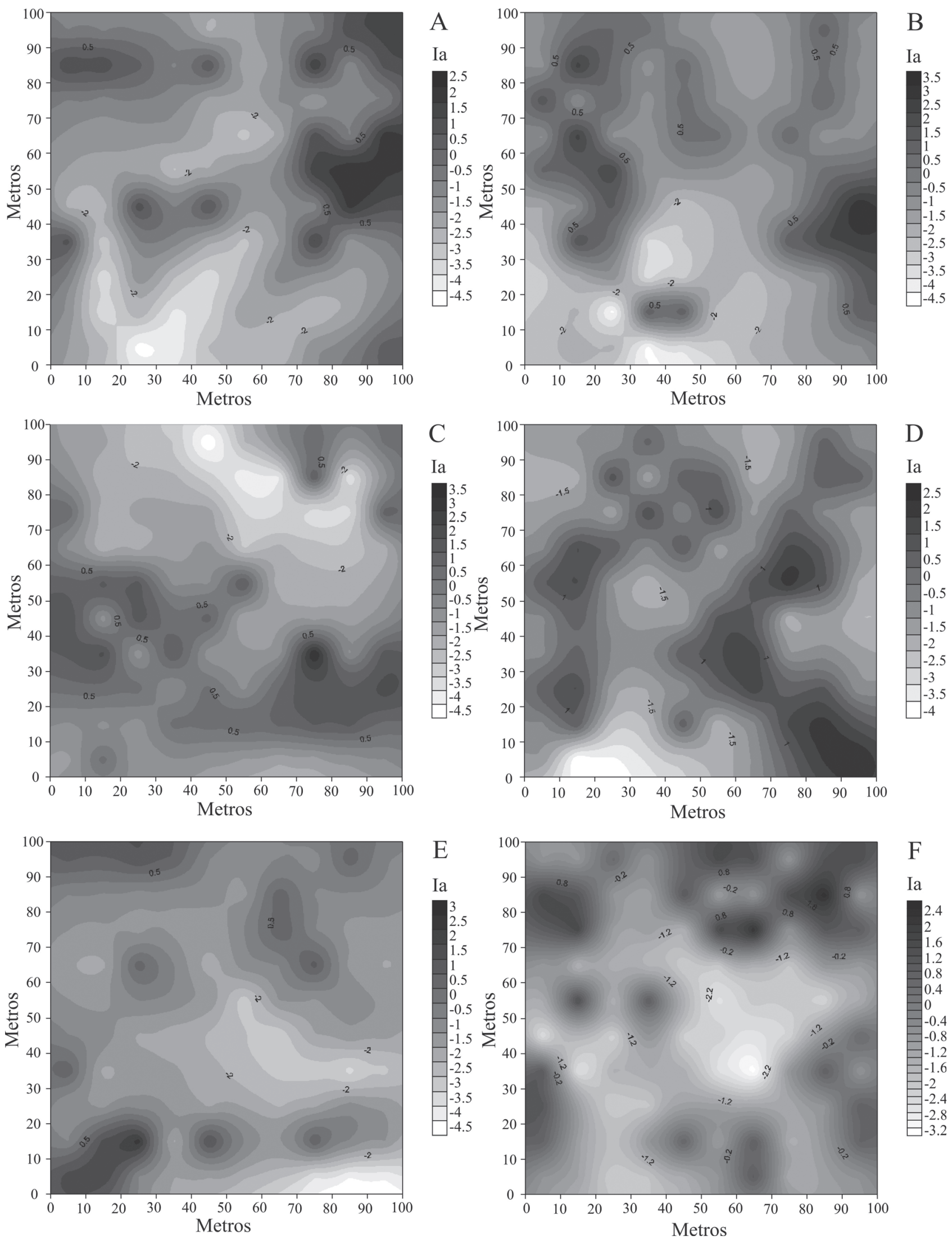

Figura 4. Diagramas de superfície das espécies com abundância $\geq 20$ indivíduos amostrados em uma floresta subtropical no sul do Brasil. A) Campomanesia guazumifolia; B) Cabralea canjerana; C) Casearia silvestris; D) Ocotea diospyrifolia; E) Cordia americana; F) Annona neosalicifolia. 

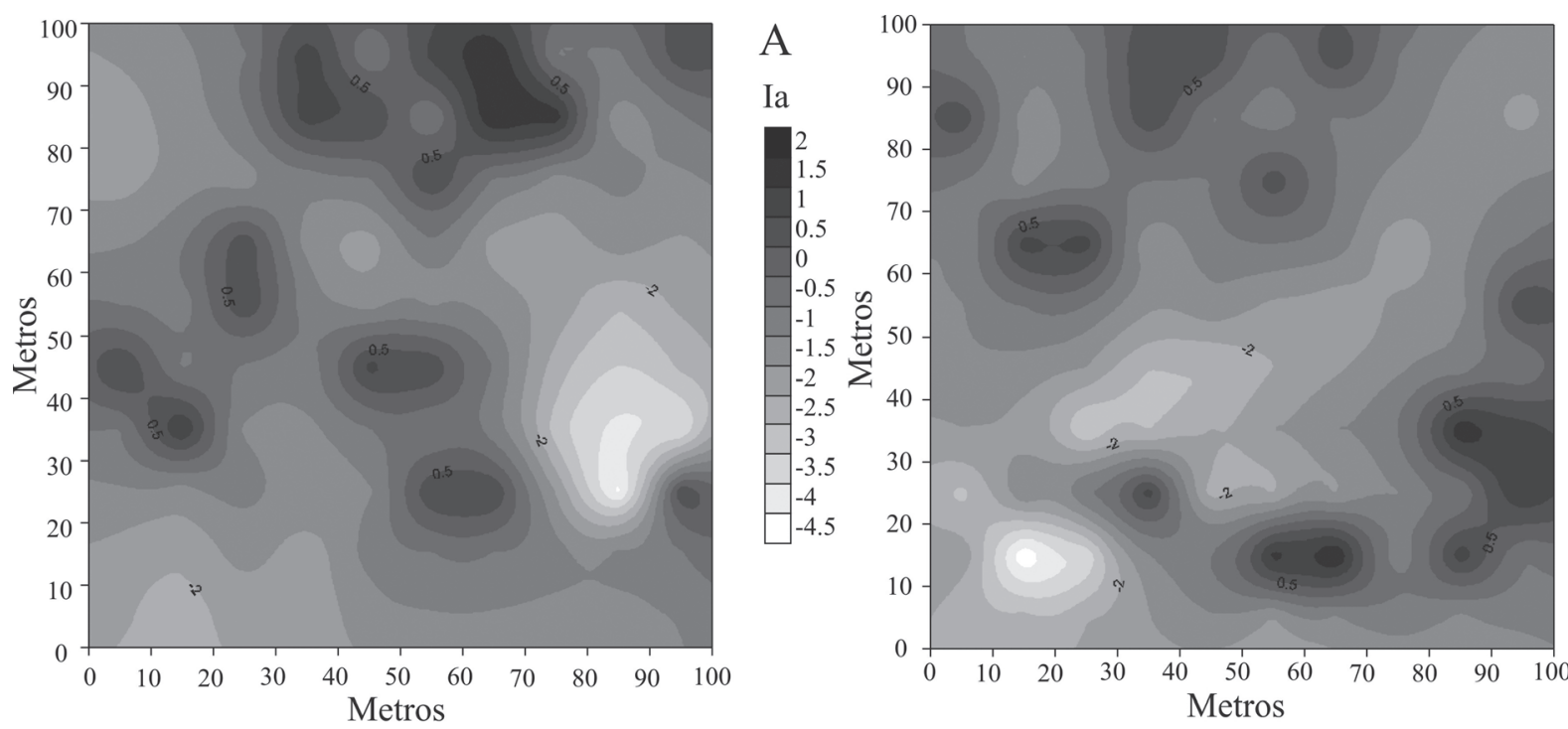

B

Ia
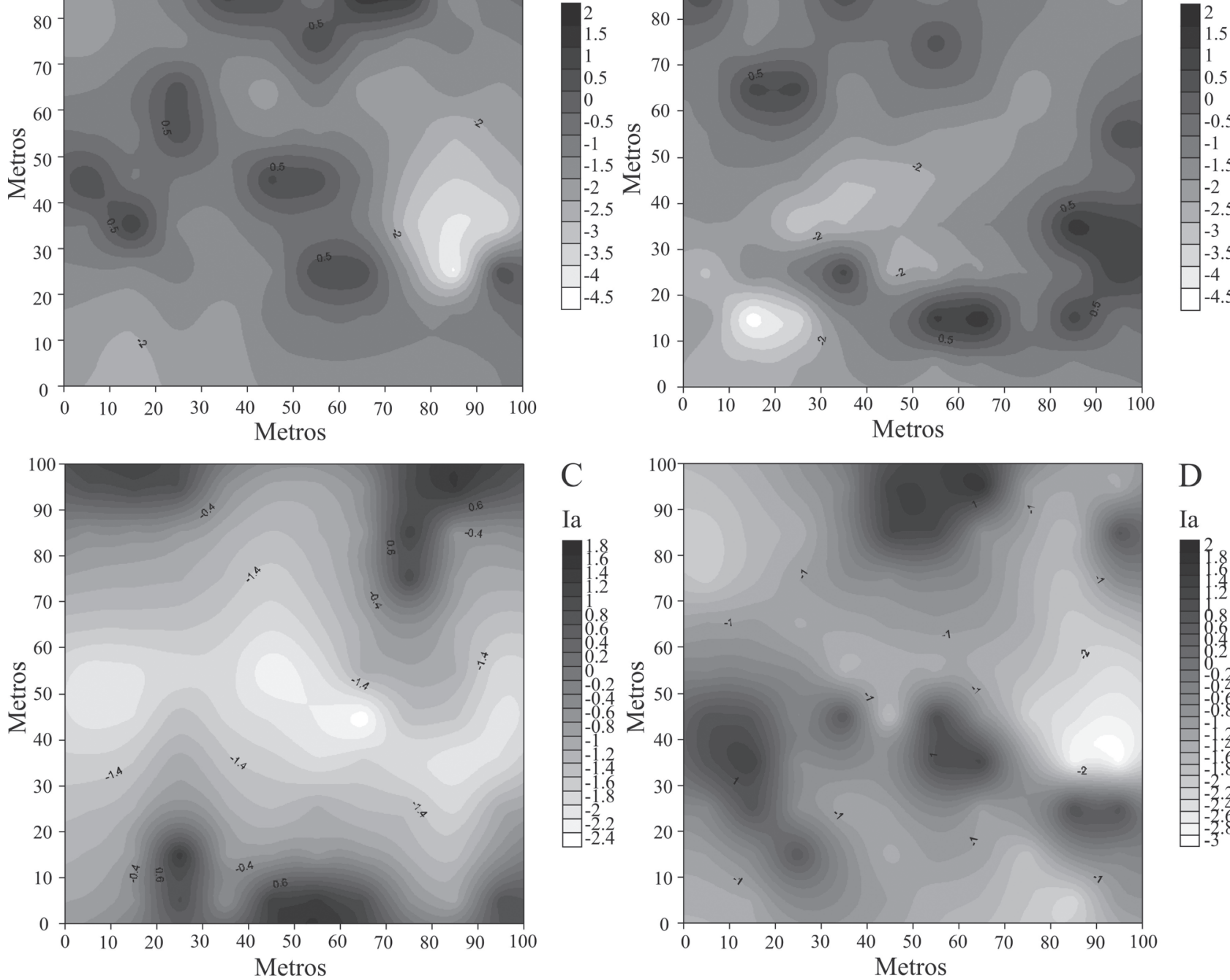

$\mathrm{C}$

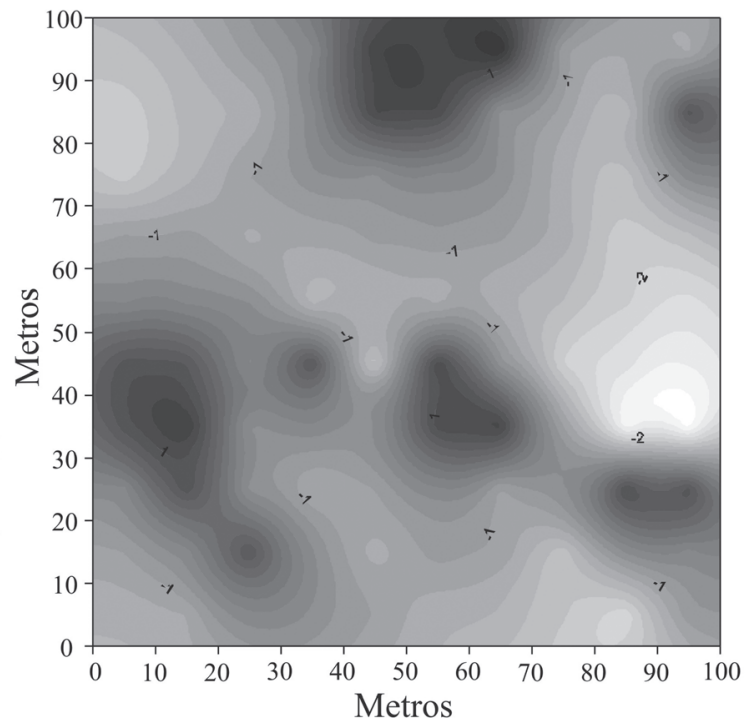

$\mathrm{D}$

Ia
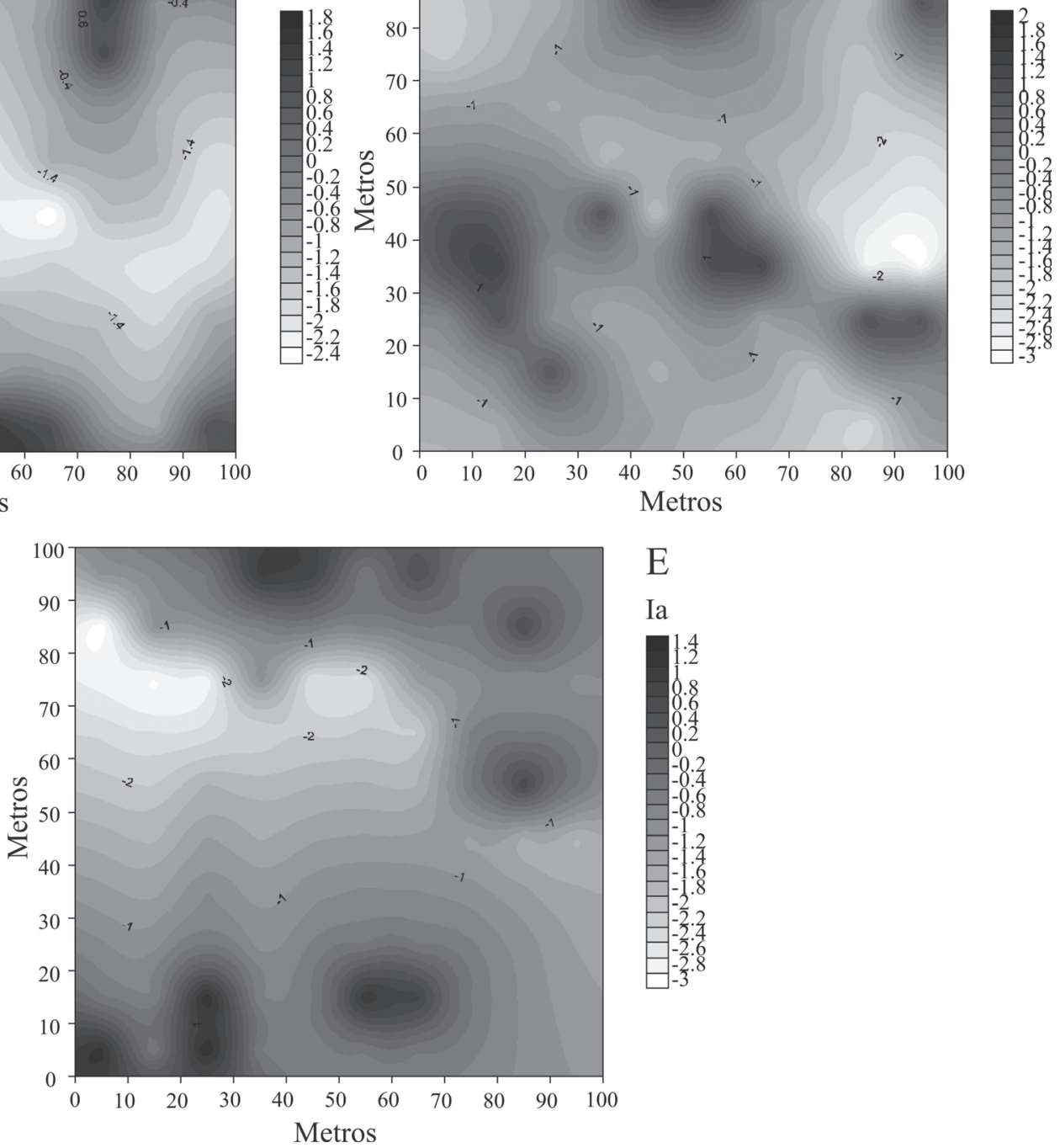

$\mathrm{E}$

Ia

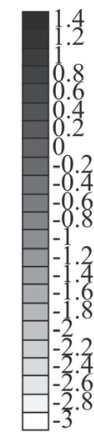

Figura 5. Diagramas de superfície das espécies com abundância $\geq 20$ indivíduos amostrados em uma floresta subtropical no sul do Brasil. A) Nectandra lanceolata; B) Cupania vernalis; C) Banara tomentosa; D) Gymnanthes concolor; E) Myrocarpus frondosus. 
Tabela 4. Índices de agregação (Ia), média de Ia para lacunas $(v j)$, média de Ia para agrupamentos (vi), correlação entre índice de agregação e riqueza específica (Ia x S) e entre índice de agregação e equabilidade (Ia x J') em uma floresta subtropical no sul do Brasil. ${ }^{*}=p<0,05 ;{ }^{* *}=p<0,01$; ${ }^{* *}=p<0,001$.

\begin{tabular}{lcccccc}
\hline \multicolumn{1}{c}{ Espécie } & $\mathrm{N}$ & $\mathrm{Ia}$ & $\mathrm{vi}$ & $\mathrm{vj}$ & $\mathrm{Iax} \mathrm{S}$ & Ia x J \\
\hline Casearia sylvestris & 223 & $1,39^{* *}$ & $1,34^{* *}$ & $-1,51^{* *}$ & $-0,09$ & $-0,55^{* * *}$ \\
Ocotea diospyrifolia & 137 & $1,39^{* *}$ & $1,21^{*}$ & $-1,29^{*}$ & $-0,14$ & $-0,28^{* * *}$ \\
Cabralea canjerana & 108 & $1,42^{* *}$ & $1,40^{* *}$ & $-1,41^{* *}$ & $0,35^{* * *}$ & 0,02 \\
Casearia decandra & 61 & $1,98^{* * *}$ & $1,88^{* * *}$ & $-1,98^{* * *}$ & $-0,02$ & $-0,18$ \\
Gymnantes concolor & 41 & 1,15 & 1,10 & $-1,15$ & 0,05 & $-0,18$ \\
Cryptocarya moschata & 38 & $1,65^{* * *}$ & $1,46^{* *}$ & $-1,65^{* * *}$ & $0,26^{* *}$ & $0,23^{* *}$ \\
Annona neosalicifolia & 35 & $1,28^{* *}$ & $1,30^{* *}$ & $-1,27^{*}$ & $0,33^{* *}$ & 0,18 \\
Banara tomentosa & 29 & 1,16 & 1,19 & $-1,15$ & 0,12 & 0,06 \\
Luehea divaricata & 29 & $1,77^{* * *}$ & $1,78^{* * *}$ & $-1,77^{* * *}$ & $0,28^{* * *}$ & 0,06 \\
Campomanesia guazumifolia & 24 & $1,56^{* * *}$ & $1,54^{* * *}$ & $-1,56^{* * *}$ & $0,17^{*}$ & 0,11 \\
Sorocea bonplandii & 24 & $1,60^{* * *}$ & $1,33^{* *}$ & $-1,59^{* * *}$ & $0,40^{* * *}$ & 0,06 \\
Cupania vernalis & 22 & $1,24^{*}$ & $1,23^{*}$ & $-1,24^{*}$ & $0,32^{* * *}$ & 0,17 \\
Lonchocarpus campestris & 22 & $1,72^{* * *}$ & $1,76^{* * *}$ & $-1,73^{* * *}$ & $0,41^{* * *}$ & $0,26^{* * *}$ \\
Cordia americana & 20 & $1,32^{* *}$ & $1,28^{*}$ & $-1,31^{* *}$ & $0,27^{* * *}$ & 0,09 \\
Ilex brevicuspis & 20 & $1,71^{* * *}$ & $1,52^{* * *}$ & $-1,71^{* * *}$ & 0,11 & $-0,06$ \\
Myrocarpus frondosus & 20 & 1,08 & 1,01 & $-1,08$ & $-0,08$ & 0,04 \\
Nectandra lanceolata & 20 & $1,25^{*}$ & 1,19 & $-1,26^{*}$ & $0,14^{*}$ & 0,06 \\
\hline
\end{tabular}

Tabela 5. Índices de associação entre espécies com abundância $\geq 20$ indivíduos amostrados em uma floresta estacional subtropical no sul do Brasil. ${ }^{*}=p<0,001$; $* *=p<0,01 ; * * * p<0,001$.

\begin{tabular}{|c|c|c|c|c|c|c|c|c|c|c|c|c|c|c|c|c|c|}
\hline & $\begin{array}{c}\text { Ann } \\
\text { neo }\end{array}$ & $\begin{array}{l}\text { Ile } \\
\text { bre }\end{array}$ & $\begin{array}{l}\text { Cor } \\
\text { ame }\end{array}$ & $\begin{array}{l}\text { Gym } \\
\text { com }\end{array}$ & $\begin{array}{l}\text { Lon } \\
\text { cam }\end{array}$ & $\begin{array}{l}\text { Myr } \\
\text { fro }\end{array}$ & $\begin{array}{l}\mathrm{Nec} \\
\text { lan }\end{array}$ & $\begin{array}{l}\text { Oco } \\
\text { dio }\end{array}$ & $\begin{array}{l}\text { Cry } \\
\text { mos }\end{array}$ & $\begin{array}{l}\text { Cab } \\
\text { can }\end{array}$ & $\begin{array}{l}\text { Sor } \\
\text { bom }\end{array}$ & $\begin{array}{l}\text { Cam } \\
\text { gua }\end{array}$ & $\begin{array}{l}\text { Ban } \\
\text { tom }\end{array}$ & $\begin{array}{l}\text { Cas } \\
\text { dec }\end{array}$ & $\begin{array}{l}\text { Cas } \\
\text { syl }\end{array}$ & $\begin{array}{l}\text { Cup } \\
\text { ver }\end{array}$ & $\begin{array}{l}\text { Lue } \\
\text { div }\end{array}$ \\
\hline Ann neo & 1,00 & & & & & & & & & & & & & & & & \\
\hline Ile bre & 0,00 & 1,00 & & & & & & & & & & & & & & & \\
\hline Cor ame & $-0,03$ & $-0,13$ & 1,00 & & & & & & & & & & & & & & \\
\hline Gym com & $-0,01$ & $-0,06$ & $-0,09$ & 1,00 & & & & & & & & & & & & & \\
\hline Lon cam & 0,04 & $-0,01$ & $0,28^{* *}$ & $-0,05$ & 1,00 & & & & & & & & & & & & \\
\hline Myr fro & 0,02 & 0,11 & 0,10 & $-0,02$ & 0,06 & 1,00 & & & & & & & & & & & \\
\hline Nec lan & 0,15 & 0,00 & $-0,04$ & 0,17 & $-0,02$ & $-0,03$ & 1,00 & & & & & & & & & & \\
\hline Oco dio & $-0,25^{*}$ & $-0,08$ & $-0,07$ & 0,10 & $-0,17$ & $-0,05$ & 0,01 & 1,00 & & & & & & & & & \\
\hline Cry mos & $-0,08$ & $-0,06$ & $-0,10$ & $-0,02$ & $-0,01$ & 0,01 & $-0,02$ & 0,07 & 1,00 & & & & & & & & \\
\hline Cab can & 0,10 & $0,42^{* *}$ & $-0,12$ & $-0,19$ & 0,05 & $-0,09$ & $-0,13$ & 0,02 & 0,09 & 1,00 & & & & & & & \\
\hline Sor bon & 0,19 & 0,00 & $-0,05$ & $0,66^{* *}$ & $-0,01$ & $-0,04$ & $0,28^{* *}$ & $-0,12$ & 0,04 & $-0,14$ & 1,00 & & & & & & \\
\hline Cam gua & $0,21^{*}$ & $0,22^{*}$ & $-0,03$ & $-0,08$ & $-0,01$ & $-0,02$ & $-0,03$ & $-0,05$ & $-0,14$ & $0,24^{*}$ & 0,04 & 1,00 & & & & & \\
\hline Ban tom & $-0,02$ & $-0,10$ & 0,07 & $-0,07$ & 0,15 & 0,05 & $-0,07$ & $-0,20$ & $-0,13$ & $-0,10$ & $-0,11$ & $-0,02$ & 1,00 & & & & \\
\hline Cas dec & $-0,16$ & $-0,07$ & 0,13 & 0,08 & $-0,18$ & $-0,08$ & 0,09 & $0,21^{*}$ & $-0,18$ & $-0,14$ & $-0,03$ & $-0,07$ & 0,06 & 1,00 & & & \\
\hline Cas syl & 0,07 & 0,14 & $-0,15$ & $-0,01$ & $-0,09$ & $-0,01$ & 0,05 & 0,07 & $-0,20^{\star *}$ & 0,19 & $-0,02$ & $-0,15$ & $-0,16$ & 0,08 & 1,00 & & \\
\hline Cup ver & 0,19 & $0,34^{* *}$ & $-0,08$ & $-0,03$ & 0,04 & $0,21^{*}$ & $0,26^{* *}$ & $-0,01$ & 0,15 & 0,10 & 0,13 & $-0,04$ & $-0,12$ & $-0,08$ & 0,06 & 1,00 & \\
\hline Lue div & 0,06 & 0,01 & 0,12 & 0,03 & $0,30^{* *}$ & $-0,02$ & 0,18 & $-0,05$ & 0,03 & $-0,04$ & $0,20^{*}$ & 0,00 & 0,01 & $-0,21^{*}$ & $-0,08$ & $-0,01$ & 1,00 \\
\hline
\end{tabular}

da área estudada aumente com o tempo, caso as pressões antrópicas e ambientais não se alterem.

Quanto aos grupos ecológicos de regeneração, dispersão e estratificação dos indivíduos, verificou-se o predomínio de espécies e indivíduos formadores do dossel, com dispersão zoocórica e dependentes de luz para germinação. Este padrão coincide com outros estudos realizados no sul do Brasil (Budke et al. 2005; Lindenmaier \& Budke 2006;
Giehl et al. 2007) sendo a zoocoria a estratégia de dispersão predominante tanto em número de indivíduos quanto em riqueza de espécies. Relacionando estratégias de dispersão e porte de indivíduos é possível perceber a predominância de espécies zoocóricas tanto entre os indivíduos emergentes quanto entre os indivíduos formadores do dossel. Tal afirmação corrobora com resultados encontrados por outros estudos realizados no sul do Brasil (Budke et al. 2005; 
Giehl et al. 2007) destacando a importância da distribuição de diásporos por animais nestas formações florestais. Os mesmos autores encontraram maior proporção de espécies zoocóricas na formação do dossel e aumento da proporção da autocoria quando considerado o número de indivíduos, sendo estes resultados semelhantes aos obtidos no presente estudo, principalmente devido ao grande número de indivíduos de Gymnanthes concolor que se encontram formando o sub-bosque da área. Por outro lado, tem-se constatado no sul do Brasil (Leyser et al. 2009; Lindenmaier \& Budke 2006) que indivíduos de espécies anemocóricas possuem em geral as maiores alturas, indicando o predomínio nas partes mais elevadas da floresta e culminando com seu aspecto fitofisionômico, ou seja, de serem espécies de grande porte caducifólias e que dispersam seus frutos pelo vento, em geral, sincronizando a dispersão com a perda foliar, conforme avaliado por Athayde et al. (2009).

Padrões de distribuição espacial podem e tem sido muito utilizados para inferir mecanismos causais de coexistência ou competição entre espécies (Wiegand 2007; Fajardo \& González 2009), uma vez concebida à premissa de que tais mecanismos atuando ao nível local geram sinais (assinaturas) que podem ser detectados e analisados por meio dos padrões espaciais (Hubbell 2001). No presente estudo, a maioria das espécies apresentou distribuição agregada em curtas distâncias, com posterior diminuição na relação de abundâncias entre as classes seguintes (aleatoriedade) e gerando, finalmente, desagregação nas maiores classes de distâncias, sobretudo para algumas espécies.

Diversos trabalhos tem demonstrado que a limitação de dispersão pode assumir um papel tão importante quanto à limitação por recursos no processo de distribuição espacial (Hardy \& Sonké 2004; Higuchi et al. 2010). Conforme discutido por McIntire \& Fajardo (2009) diversas espécies mudam de um padrão agregado nos estádios de plântulas ou jovens para um padrão regular ou de distribuição aleatória quando adultos. Este padrão de substituição, regulado por uma mortalidade dependente de densidade pode ocasionar a formação de pequenos agrupamentos (agregações), porém, dispersos de forma aleatória quando utilizadas escalas maiores de observação (Luo et al. 2012).

Processos de agrupamentos em pequenas manchas são comuns para espécies de pequeno porte e tolerantes à sombra, como Gymnanthes concolor e Sorocea bonplandii (Giehl et al. 2007), as quais foram observadas com forte associação ao longo da área. Ainda segundo estes autores, além de serem tolerantes à sombra, estas espécies possuem baixa competição intra-específica e exibem alto poder competitivo interespecífico com outras plântulas durante o estabelecimento inicial. Neste sentido, pode-se sugerir que ocorrem interações positivas entre estas espécies em seus estádios iniciais de desenvolvimento, ou pelo menos, que estas espécies exploram o espaço de maneira semelhante, gerando uma diferenciação espacial de nicho (McIntire \& Fajardo 2009).
A influência das estratégias de dispersão tem sido documentada e possibilita questionar se a limitação à dispersão das espécies pode modificar a estrutura da comunidade interferindo na riqueza de espécies e dinâmicas de composição de populações tanto espacial quanto temporalmente em florestas, principalmente tropicais e subtropicais (Nathan \& Muller-Landau 2000; Schupp et al. 2002). Além disto, a agregação de indivíduos zoocóricos adultos pode ser dada pelo acúmulo pontual de diásporos, devido principalmente ao comportamento animal, onde o acúmulo das sementes pode ser explicado pela deposição das mesmas em locais de frequência rotineira dos dispersores, como ninhos e trilhas $\mathrm{e}$ às diferenças dos fatores limitantes ao estabelecimento de plântulas na comunidade, que, usualmente apresentam padrão heterogêneo (Schupp et al. 2002; Giehl et al. 2007).

$\mathrm{Da}$ mesma forma que foram observadas interações positivas, o agrupamento de certas espécies diminuiu a equabilidade em certas unidades amostrais, demonstrando que algumas espécies com fortes adensamentos podem efetivamente diminuir a presença de outras. Os agrupamentos de Casearia sylvestris formaram dissociações com quase todas as espécies, evidenciando este padrão. Lindenmaier \& Budke (2006) encontraram resultados similares para agrupamentos de Eugenia ramboi em um remanescente de Floresta Estacional na bacia do rio Jacuí, no sul do Brasil. Apesar de não terem sido avaliadas as condições físico-químicas do solo, a predominância da distribuição espacial agrupada em pequenas manchas difusas (anisotrópicas) sugere que as características do solo não sejam o principal fator associado à atual estrutura do remanescente florestal. Isto pode indicar que a dinâmica associada ao histórico de chegada dos diásporos (limitação de dispersão) possa ter moldado a ocorrência de pequenas manchas, estruturadas a posteriori por fatores locais como características do hábitat. Neste sentido, pode-se esperar que na ausência de distúrbios na área, além de um aumento considerável de área basal, é provável que as espécies vão se distribuir formando pequenos agrupamentos, associados com um ambiente favorável ao desenvolvimento de indivíduos de grande porte e que possam estar igualmente distantes de outros indivíduos adultos da mesma espécie.

\section{Agradecimentos}

Os autores agradecem à Prefeitura Municipal de Faxinalzinho e à Secretaria Estadual de Meio Ambiente do Rio Grande do Sul, pelo apoio logístico e financeiro. Ao CNPq (processo 483775/2007-0) pelo apoio financeiro e à Universidade Regional Integrada do Alto Uruguai e das Missões - URI, Campus de Erechim, pela concessão de bolsas de estudo e apoio logístico no desenvolvimento deste trabalho. Os autores agradecem a todos os proprietários rurais que permitiram acesso aos remanescentes florestais ao longo do Projeto Áreas Protegidas - Faxinalzinho e em especial, ao Sr. Fontana, pelo apoio na realização deste estudo. Aos revisores anônimos, pelas sugestões e recomendações. 


\section{Referências}

Athayde, E.A.; Giehl, E.L.H.; Budke, J.C.; Gesing, J.P.A. \& Eisinger, S.M. 2009. Fenologia de espécies arbóreas em uma floresta ribeirinha em Santa Maria, sul do Brasil. Revista Brasileira de Biociências 7: 43-51.

Bernardi, S. \& Budke, J.C. 2010 Estrutura da sinúsia epifítica e feito de borda em uma área de transição entre Floresta Estacional Semidecídua e Floresta Ombrófila Mista. Floresta 40: 81-92.

Budke, J.C.; Giehl, E.L.H.; Athayde, E.A.; Eisinger, S.M. \& Záchia, R.A. 2004. Florística e fitossociologia do componente arbóreo de uma floresta ribeirinha, arroio Passo das Tropas, Santa Maria, RS, Brasil. Acta Botanica Brasilica 18: 581-589.

Budke, J.C.; Athayde, E.A.; Giehl, E.L.H.; Záchia, R.A. \& Eisinger, S.M. 2005. Composição florística e estratégias de dispersão das espécies lenhosas em um trecho de floresta ribeirinha de Santa Maria, Rio Grande do Sul, Brasil. Iheringia, Série Botânica 51: 17-24.

Budke, J.C.; Jarenkow, J.A. \& Oliveira-Filho, A.T. 2007. Relationships between tree component structure, topography and soils of a riverine forest, Rio Botucaraí, Southern Brazil. Plant Ecology 189: 189-200.

Budke, J.C.; Jarenkow, J.A. \& Oliveira-Filho, A.T. 2008. Tree community features of two stands of riverine forest under different flooding regimes in Southern Brazil. Flora 203: 162-174.

Costa, R.C \& Santos, F.A.M. 2011. Padrões espaciais de Qualea grandiflora Mart. em fragmentos de cerrado no estado de São Paulo. Acta Botanica Brasilica 25: 215-222.

Dale, M.R.T. 1997. Spatial pattern analysis in plant ecology. Cambridge, Cambridge University Press.

Dale, M.R.T.; Dixon, P.; Fortin, M.J.; Legendre, P.; Myers, D.E. \& Rosenberg, M.S. 2002. Conceptual and mathematical relationships among methods for spatial analysis. Ecography 25: 558-577.

Fajardo, A. \& González, M.E. 2009. Replacement patterns and species coexistence in an Andean Araucaria-Nothofagus forest. Journal of Vegetation Science 20: 1176-1190.

Giehl, E.L.H.; Athayde, E.A.; Budke, J.C.; Gesing, J.P.A.; Eisinger, S.M. \& Canto-Dorow, T.S. 2007. Espectro e distribuição vertical das estratégias de dispersão de diásporos do componente arbóreo em uma floresta estacional no sul do Brasil. Acta Botanica Brasilica 21: 137-145.

Glenn-Lewin, D.C. \& van der Maarel, E. 1992. Patterns and process of vegetation dynamics. Pp. 11-44. In: Glenn-Lewin, D.C.; Peet, R.K.; \& Veblen, T.T. (Eds.). Plant succession: theory and Prediction. London, Chapman and Hall.

Gilbert, B. \& Lechowics, M.J. 2004. Neutrality, niches, and dispersal in a temperate forest understory. Proceedings of the National Academy of Sciences 101: 7651-7656.

Hardy, O.J. \& Sonké, B. 2004. Spatial patterns of tree species distribution in a tropical rain forest of Cameroon: assessing the role of limited dispersal and niche differentiation. Forest Ecology and Management 197: 191-202.

Higuchi, P.; Silva, A.C.; Louzada, J.N.C. \& Machado, E.L.M. 2010. Spatial patterns of a tropical tree species growing under a eucalyptus plantation in South-East Brazil. Brazilian Journal of Biology 70: 271-277.

Hubbell, S.P. 2001. The unified neutral theory of biodiversity and biogeography. Princeton, Princeton University Press.

Jarenkow, J.A \& Budke, J.C. 2009. Padrões florísticos e análise estrutural de remanescentes de Florestas com Araucária no Brasil. Pp. 113-126. In: Fonseca, C.R.; Souza, A.F.; Leal-Zanchet, A.M.; Dutra, T.; Backes, A. \& Ganade, G. (Orgs.). Floresta com araucária: ecologia, conservação e desenvolvimento sustentável. Ribeirão Preto, Holos Editora.

Jarenkow, J.A. \& Waechter, J.L. 2001. Composição, estrutura e relações florísticas do componente arbóreo de uma floresta estacional no Rio Grande do Sul. Revista Brasileira de Botânica 24: 263-272.

Köppen, W. 1948. Climatologia: con un estudio de los climas de la tierra. Mexico, Fondo de Cultura Econômica.

Legendre, P. \& Fortin, M.J. 1989. Spatial pattern and ecological analysis. Vegetatio 80: 107-138.

Legendre, P. \& Legendre, L. 1998. Numerical Ecology. Amsterdam, Elsevier.
Leyser, G.; Viniski, M.; Donida, A.L.; Zanin, E.M. \& Budke, J.C. 2009 Espectro de dispersão em um fragmento de transição entre Floresta Ombrófila Mista e Floresta Estacional na região do Alto Uruguai, Rio Grande do Sul, Brasil. Pesquisas, Botânica 60: 355-366.

Lindenmaier, D.S. \& Budke, J.C. 2006 Florística, diversidade e distribuição espacial das espécies arbóreas em uma floresta estacional na bacia do rio Jacuí, sul do Brasil. Pesquisas, Botânica 57: 193-216.

Luo, Z.R.; Yu, M.J.; Chen, D.L.; Wu, Y.G. \& Ding, B.Y. 2012. Spatial associations of tree species in a subtropical evergreen broad-leaved forest. Journal of Plant Ecology 5: 1-10.

McIntire, E.J.B. \& Fajardo, A. 2009. Beyond description: the active and effective way to infer process from spatial patterns. Ecology 90: 46-56

Mueller-Dombois, D. \& Ellenberg, H. 1974. Aims and methods of vegetation ecology. NewYork, Wiley \& Sons.

Nathan, R. \& Muller-Landau, H.C. 2000 Spatial patterns of seed dispersal, their determinants and consequences for recruitment. Trends in Ecology and Evolution 15: 278-285.

Oliveira-Filho, A.T.; Vilela, E.A.; Carvalho, D.A. \& Gavilanes, M.L. 1994. Effects of soils and topography on the distribution of tree species in a tropical riverine forest in south-eastern Brazil. Journal of Tropical Ecology 10: 483-508.

Oliveira-Filho, A.T.; Jarenkow, J.A. \& Rodal, M.J.N. 2006. Floristic relationships of Seasonally Dry Forest of eastern South American based on tree species distribuion patterns. Pp. 159-192. In: Pennington, R.T.; Lewis, G.P. \& Ratter, J.A. (Orgs.). Neotropical savannas and dry forests: plant diversity, biogeography and conservation. Boca Raton, CRC Press.

Perry, J. N. 1998. Measures of spatial pattern for counts. Ecology 79: 1008-1017.

Perry, J.N.; Bell, E.D.; Smith, R.H. \& Woiwod, I.P. 1998. SADIE: software to measure and model spatial pattern. Aspects of Applied Biology 46: 95-102.

Perry, J.N.; Wilder, L.; Holland, J.M. \& Alston, R.D. 1999. Red-blue plots for detecting clusters in count data. Ecology Letters 2: 106-113.

Perry, J.N.; Liebhold, A.M.; Rosenberg, M.S.; Dungan, J.L.; Miriti, M.N. \& Citron-Pousty, S. 2002. Illustration and guidelines for selecting statistical methods for quantifying spatial patterns in ecological data. Ecography 25: 578-600.

Poulos, H.M. \& Camp, A.E. 2010. Topographic influences on vegetation mosaics and tree diversity in the Chihuahuan Desert Borderlands. Ecology 91: 1140-1151.

Rosenberg, M.S. \& Anderson, C.D. 2011. PASSaGE: pattern analysis, spatial statistics and geographic exegesis, version 2. Methods in Ecology and Evolution 2: 229-232.

Schupp, E.W.; Milleron, T. \& Russo, S. 2002. Dissemination limitation and the origin and maintenance of species-rich tropical forests. Pp. 19-33. In: Levey, D.J.; Silva, W.R. \& Galleti, M. (Eds.). Seed dispersal and frugivory: ecology, evolution and conservation. New York, CABI Publishing.

Sobral, M.; Jarenkow, J.A.; Brack, P.; Irgang, B.; Larocca, J. \& Rodrigues, R.S. 2006. Flora arbórea e arborescente do Rio Grande do Sul, Brasil. São Carlos, RiMA/Novo Ambiente.

Golden Software, 2002. Surfer 8.0: Contouring and 3d surface mapping for scientists and engineers. User's Guide. New York, Golden Software.

Swaine, M.D. \& Whitmore, T.C. 1988. On the definition of ecological species groups in tropical rain forests. Vegetatio 75: 81-86.

Tuomisto, H.; Ruokolainen, K. \& Yli-Halla, M. 2003. Dispersal, environment, and floristic variation of western Amazonian forests. Science 299: 241-244

Van Der Pijl, L. 1982. Principles of dispersal in higher plants. New York, Springer Verlag.

Wiegand, T.; Gunatilleke, S. \& Gunatilleke, N. 2007. Species association in a heterogeneous Sri Lankan dipterocarp forest. The American Naturalist 170: E77-E95.

Zar, J.H. 1996. Biostatistical analysis. New Jersey, Prentice-Hall. 